\title{
Orhan Pamuk: sentimentos pátrios nas ruas de São Paulo ${ }^{1}$
}

Como ávido leitor da obra romanesca e ensaística de Orhan Pamuk, autor turco Prêmio Nobel de Literatura em 2006, há dois anos tive uma surpresa: encontrei um livro seu que eu não conhecia na pequena livraria da estação Alexanderplatz em Berlim, quando passava alguns dias na cidade. O livro era Der Blick aus meinem Fenster (2008), "A vista da minha janela", e trazia na capa, muito a propos, uma foto do autor no terraço do seu apartamento em Istambul com os dois minaretes da mesquita de Cihangir logo em frente e o Estreito de Bósforo ao fundo. Abri o livro e verifiquei o índice. Tratava-se de uma coletânea de ensaios. Ao passar os olhos pelos seus títulos, tive uma nova surpresa, ainda maior que a primeira: um deles tematizava a cidade de São Paulo, a minha cidade, onde nasci, cresci e sempre morei. Comprei o livro imediatamente e saí.

De volta ao Brasil, descobri que o pequeno ensaio intitulado em alemão Heimatliche Gefühle in den Straßen São Paulos ("Sentimentos pátrios nas ruas de São Paulo") ainda não havia sido traduzido nem no país nem aparentemente no mundo de língua inglesa. A sua única tradução publicada parecia ter sido essa alemã.

Para a realização deste trabalho, obtive a gentil permissão da Wylie Agency de Londres, Reino Unido, à qual expresso aqui os meus mais sinceros agradecimentos. 
Nesse livro se encontra um punhado de textos curtos que Pamuk escreveu ao longo da vida, alguns dos quais estão incluídos também em Other Colors - Essays and a Story, sua coletânea de ensaios por assim dizer oficial, lançada pela Alfred Knopf de Nova York na tradução inglesa de Maureen Freely pela primeira vez em 2007. "A vista da minha janela", que dá nome à edição alemã, é de fato uma alusão a essa 'story' do subtítulo da edição inglesa, um conto autobiográfico ali chamado To Look Out The Window e também incluído na edição alemã, com o título equivalente Aus dem Fenster schauen. Talvez por motivos políticos, ou até mesmo comerciais, o autor tenha escolhido não incluir na coletânea inglesa o texto que apresento aqui, que só aparece, portanto, na edição alemã.

"Sentimentos pátrios nas ruas de São Paulo" poderia ser definido, à primeira vista, como um ensaio comparativo entre a cidade de São Paulo e a Istambul natal de Pamuk, segundo as impressões que ele colheu de algumas caminhadas que fez pelas ruas do centro da capital paulista, supostamente quando veio ao Brasil para a Festa Literária Internacional de Parati (FLIP), em 2005.

Uma vez que traduzi o ensaio a partir da tradução alemã de Gerhard Meier, publicada na edição alemã acima mencionada, transcrevo primeiramente essa versão, seguida da minha tradução e de um breve comentário: 


\section{Heimatliche Gefühle in den Straßen São Paulos}

Ich ging in São Paulo frühmorgens aus dem Haus und spazierte stundenlang wie elektrisiert durch die Straßen. Wieder einmal wurde mir aufs schönste bestätigt, was für ein Faible ich für Lateinamerika habe. Mir gefallen die muffigen kleinen Läden voller vergilbter Bücher, das müde, unaufgeregte Gebaren der Leute, die Zeitungskiosks auf den Boulevards, die spürbare Energie auf den Straßen, die Gesichter der Menschen, die Lokale und Imbißbuden, in die ich mich manchmal setze, die freundschaftliche Art, in der die Leute ohne weiteres miteinander ins Gespräch kommen. Selbst der Armut hier kann ich etwas abgewinnen, aber nur deshalb, weil sie mich an die Türkei erinnert. Ich mag, wie bescheiden die Leute hier wirken, wie fest sie mitten im Leben stehen, mag das fröhliche Lachen der Leute, die vor den Cafés sitzen, die vollgepferchten alten Busse, das kalte Neonlicht in den Lokalen, das Brummen und Britzeln der Kühlschränke. Ich mag auch die moderne Verfallenheit dieser Stadt, die alten Häuser, deren Fassaden so fahl aussehen wie die Haut eines Kranken. Wenn ich diese Mischung von Armut und Energie, aus Wille und Empfindlichkeit, Ehrgeiz und Mittellosigkeit, dann kommt mir unwillkürlich in den Sinn, was wir Türken für einen Komplex mit uns herumschleppen und wie sehr uns diese Menschen darin ähneln. Ich ging in die Verkaufspassagen, in denen Weißwaren, Digitalkameras, Videos und natürlich DVDs feilgeboten wurden. Ich spürte regelrecht, wie abgekämpft und doch hoffnungsvoll all die Leute waren, die sich an den Schaufenstern vorbeidrängten. Diese Menschen vermittelten mir ein Gefühl, wie es mir inmitten des Reichtums der großen Städte Nordamerikas und Europas nicht zuteil wird: Ich glaube diese Leute zu kennen und zu wissen, was sie fühlen, oder zumindest bilde ich mir das ein. Sie werden jetzt die Dinge kaufen, die sie in den Passagen gesehen haben, die DVDs, die Schmuckstücke, die Geräte, und dann werden sie damit in ihr gemütliches Heim gehen und dort glücklich sein! Mir wird hier klar, wie gut ich selbst das Gefühl kenne, wenn man sich an einem kalten Wintertag in eine Einkaufspassage flüchtet, dort irgend etwas ersteht, an dem man sich dann zu Hause satt sehen und erfreuen kann. Und ich weiß auch aus eigener Anschauung, daß außerhalb des Westens die meisten Menschen im Durcheinander solch einer bedürftigen, aber hoffnungsvollen Welt 
leben. Auf dem großen Platz im Stadtzentrum und im Park hinter der Kathedrale dämmerten Obdachlose auf matratzenbelegten kaputten Bänken dahin. Auf den Plätzen, auf denen es genau wie in Istanbul ständig von einfachem Volk wimmelte, boten Quacksalber Pulver und Heilmittel gegen jede Art von Zipperlein feil und wurden dabei von Handlangern theatralisch unterstützt. Fliegende Händler breiteten auf den Gehsteigen große Plastikplanen aus wie Bettücher und verkauften darauf allerlei Zeug wie Raubkopien von DVDs und billige Hemden. Von der Polizei, die auf mich brutaler wirkte als die türkische, wurden sie immer wieder davongejagt. Ich hatte mich schon ziemlich müde gelaufen, überwand mich aber und zog an diesem Wintertag, an dem das Wetter eher an den Istanbuler Spätsommer erinnerte, weiter durch die endlosen Straßen, wobei ich mich immer wieder verlief. Einmal betrat ich eine hochwandige Eisenwarenhandlung, deren Tür weit offenstand, und besah mir verdutzt das wunderbare Sammelsurium von Wasserhähnen, elektrischen Schaltern, Bohren, Thermosflaschen, emaillierten Tee- und Kaffeekannen, Winkelrohren, billigen Lampen und Farbflaschen. Hundert Meter weiter staunte ich nicht weniger, als ich in einer riesigen Buchhandlung zahllose abgegriffene Bücher aus den fünfziger und sechziger Jahren vorfand, liebevoll aufgereiht von Verkäufern, die von ihrer Kleidung und ihrem ganzen Habitus her nicht anders wirkten als Türken oder Menschen aus anderen ärmlichen Ländern. Unter anderem stieß ich auf einer Übersetzung von Gallands Märchen aus tausendundeiner Nacht... Ich liebe solche randständigen, an der Schwelle zur modernen Welt befindlichen Orte, die sich von all ihrer Verlassenheit und Provinzialität dennoch nicht unterkriegen lassen, und ich fühle mich dieser besonderen Welt zugehörig. Und wenn ich mich von dieser Welt zu weit entferne, mich etwa vom Glanz New Yorks oder ähnlicher Städte zu sehr blenden lasse, dann fürchte ich, daß tief in mir drinnen sich etwas abnützt und ich mich zu weit von zu Hause entfernt habe.

\section{Sentimentos pátrios nas ruas de São Paulo}

Saí de casa de manhã cedo em São Paulo e passeei pelas ruas da cidade como que eletrizado. Mais uma vez, e da maneira mais bela, vi confirmada a fraqueza que tenho pela América Latina. Gosto das lojinhas 
mofadas repletas de livros amarelecidos, do porte sonolento e despreocupado das pessoas, das bancas de jornal nas avenidas, da energia que se sente nas ruas, dos rostos das pessoas, dos restaurantes e botequins, nos quais às vezes me sento, do modo amigável como as pessoas puxam conversa umas com as outras sem dificuldade. Posso encontrar um certo prazer até mesmo na pobreza daqui, mas apenas porque ela me lembra a Turquia. Gosto da modéstia do povo daqui, do modo realista com que ele encara a vida, gosto do sorriso alegre das pessoas que se sentam na frente dos cafés, dos ônibus velhos abarrotados de gente, da luz fria de neon nos restaurantes, do ruído dos refrigeradores. Gosto também da decadência moderna desta cidade, das casas velhas, cujas fachadas parecem tão descascadas como a pele de um doente. Quando vejo essa mistura de pobreza e de energia, de vontade e de sensibilidade, de ambição e de falta de recursos, penso involuntariamente no complexo que nós turcos arrastamos conosco e no quanto essas pessoas se assemelham a nós nisso. Passei pelas galerias nas quais eram vendidos tecidos, câmeras digitais, vídeos e certamente DVDs. Notei realmente quão esgotadas e ao mesmo tempo esperançosas estavam todas aquelas pessoas que se aglomeravam diante das vitrines. Essas pessoas me transmitiram uma sensação que não sinto em meio à riqueza das grandes cidades da América do Norte e da Europa: creio conhecer essas pessoas e saber o que elas sentem, ou pelo menos imaginá-lo. Agora elas vão comprar as coisas que viram nas galerias, os DVDs, as joias, os aparelhos, e depois ir para o seu aconchegante lar com o que adquiriram e ser felizes! Aqui fica claro para mim quão bem eu mesmo conheço a sensação de fugir para uma galeria num dia frio de inverno e adquirir algo com o que se possa fartar-se de ver e de aproveitar. E sei também, por experiência própria, que fora do ocidente a maior parte das pessoas vive na desordem desse mundo carente, mas esperançoso. Na grande praça no centro da cidade e no parque atrás da catedral os mendigos amanheciam em bancos quebrados cobertos de colchões. Nas praças, apinhadas o tempo todo de gente humilde exatamente como em Istambul, charlatões vendiam pós e remédios contra qualquer espécie de gota enquanto recebiam um apoio teatral de alguns ajudantes. Os ambulantes estendiam grandes lonas de plástico feito toalhas de mesa nas calçadas e vendiam nelas todo tipo de bugigangas, como cópias piratas de DVDs e camisas baratas. Nisso eram perseguidos às carreiras repetidas vezes pela 
polícia, que me pareceu mais violenta que a turca. Já estava bastante cansado de andar, mas me recuperei e continuei pelas ruas sem fim nas quais sempre me perdia, neste dia de inverno, em que o tempo lembrava mais o verão tardio de Istambul. Uma vez entrei numa loja de ferragens de paredes altas, cuja porta estava aberta até o canto, e examinei perplexo a maravilhosa mixórdia de torneiras, interruptores elétricos, furadeiras, garrafas térmicas, bules de café e de chá esmaltados, cantos de tubos, lâmpadas baratas e garrafas coloridas. Não fiquei menos surpreso quando, cem metros adiante, encontrei num enorme sebo inúmeros livros esgotados dos anos cinquenta e sessenta, enfileirados com carinho por vendedores que, a julgar pelas suas roupas e hábitos, não eram diferentes dos turcos ou de gente de outros países pobres. Entre outras coisas, me deparei com uma tradução de As Mil e uma Noites de Galland... Adoro esses lugares periféricos que se encontram no limiar do mundo moderno, que não desanimam nem apesar de todo o seu abandono e provincianismo, e me sinto parte desse mundo específico. E se me afasto muito desse universo, se me deixo deslumbrar demais pelo esplendor de Nova York ou de cidades semelhantes, então temo que algo lá no fundo dentro de mim se deteriore e que eu tenha me afastado demais de casa.

Sim, a primeira ideia que vem à mente do paulistano ao concluir a leitura é a de que o título do texto estaria ainda mais apropriado se fosse: "Sentimentos pátrios nas ruas do centro de São Paulo". A descrição desse espaço-cenário e do material humano que o povoa é fidedigna, mas o centro de São Paulo é certamente apenas uma pequena parte da cidade que, devemos dizer, de maneira nenhuma pode ser representativa do conjunto. Tomar a parte pelo todo é sempre um risco, sobretudo quando se quer falar de uma cidade de tamanha pluralidade e heterogeneidade como a nossa, tanto no aspecto arquitetônico quanto no humano. Nesse ensaio, o leitor estrangeiro que não conhece São Paulo é informado apenas quanto à realidade do centro da cidade e não à realidade da cidade. Ele não 
toma contato com o fato de que em São Paulo há também muita riqueza, limpeza, progresso e modernidade, e de que se trata aqui de uma metrópole imensa e cosmopolita, da cidade que é a mais rica, a maior e a mais populosa do Brasil, conhecida há tempos como a "locomotiva do país" (embora o termo já tenha caído em desuso, o conceito ainda permanece).

Quando o autor afirma: "Gosto da modéstia do povo daqui [...]", "Gosto também da decadência moderna desta cidade, as casas velhas, cujas fachadas parecem tão descascadas como a pele de um doente", ou ainda: "Adoro esses lugares periféricos que se encontram no limiar do mundo moderno, que não desanimam nem apesar de todo o seu abandono e provincianismo [...]", ele evidentemente não está descrevendo as características da cidade de São Paulo, como um todo, que é bem diversa, mas as características do centro da cidade de São Paulo, por onde ele caminhou. Quem passeia, no entanto, pela Avenida Paulista, símbolo da metrópole, ou por bairros como Perdizes, Pacaembu, Higienópolis, Pinheiros, Vila Madalena, os Jardins, City Lapa, Vila Nova Conceição, Ibirapuera, Morumbi, Chácara Santo Antônio, Itaim, Brooklin, Vila Olímpia, Moema e outros, que, juntos, compõem uma parcela significativa da cidade, não encontra exatamente "modéstia", "decadência", "casas velhas descascadas" ou "abandono e provincianismo", mas uma opulência de auto-estima, vaidade e orgulho, de modernidade, de progresso e de constante desenvolvimento urbano.

Tal tendência de tomar o centro da cidade como paisagem representativa do conjunto deriva possivelmente do fato de que, nas grandes cidades da América do Norte e da Europa, de que fala Pamuk no ensaio, o centro é geralmente o local mais belo, mais nobre, mais valorizado e mais característico da personalidade da cidade por inteiro. No Brasil, e acima de tudo em São Paulo, o que se verifica hoje em dia, é claro - é justamente o inverso. É nos bairros, afastados do centro, que hoje se encontra desenvolvimento, riqueza e limpeza na capital paulista. O centro, por sua vez, possui uma feição e um caráter muito peculiares, muito pitorescos, que não podem ser 
encontrados em nenhum outro ponto da cidade, nem mesmo nas suas regiões mais pobres e decadentes, como as periferias e algumas partes da Zona Norte e da Zona Leste. Também por esse motivo, de maneira nenhuma se pode tomar o centro como um cenário representativo da cidade, do país, ou até mesmo do continente, como temos a impressão de ser o caso no texto de Pamuk.

A despeito de tudo isso, é preciso reconhecer que essa generalização da pobreza e da decadência de São Paulo não é gratuita, mas serve no texto a um propósito bem definido: o propósito humanístico. É uma representação que permitiu a Pamuk traçar de uma maneira coerente algumas semelhanças entre São Paulo e a sua amada Istambul, e dar vazão às suas sensações de familiaridade e identificação com a capital paulista, no caso a região da Praça da República, da Avenida Ipiranga, do Largo São Bento (Rua Florêncio de Abreu), da Praça da Sé e da Santa Ifigênia, conforme algumas passagens do seu ensaio nos levam a crer. Essa representação, assim, serve ao objetivo humanístico da aproximação entre duas cidades, dois países e dois povos geograficamente tão distantes e historicamente tão distintos, e tal aproximação é facilitada aqui pelo recurso ao estereótipo, bem como pelo da generalização de atributos notadamente regionais.

Ao estudar os romances e ensaios do autor em cujo centro se encontram a cidade de Istambul e a vida na Turquia, também nós paulistanos e brasileiros de outros Estados percebemos sem dificuldade os paralelos que se podem traçar entre aquela realidade e a nossa, sobretudo no que diz respeito à vergonha e ao complexo de inferioridade em relação à cultura europeia que a inteligência de ambos os países arrasta consigo dolorosamente há séculos. Somado a pontos em comum entre São Paulo e Istambul também no tocante às dificuldades com transporte público, trânsito, superpopulação, barulho e diversos outros fatores ${ }^{2}$, isso nos faz sentir uma familiarida-

Para essas e outras semelhanças entre São Paulo e Istambul, ver, por exemplo, MILTON, John. Retratos de viagens: Turquia, Bálcãs e Egito. São Paulo: Hedra, 2010. 
de e uma identificação com a capital turca semelhantes àquelas que Pamuk afirma sentir com o nosso centro de São Paulo no que diz respeito à pobreza, à decadência e ao atraso encontrados ali.

Por fim, quis traduzir e comentar esse ensaio não por amor à atividade tradutória ou crítica per se, embora esse amor também exista, mas, primeiramente, pela crença no que o autor chamou certa vez de "irmandade dos livros e dos leitores" - a irmandade criada pela arte literária, que aproxima e unifica os livros e os leitores, por meio do humano, em todos os lugares e em todas as épocas.

E o presente ensaio é justamente isto: uma autêntica obra de arte literária, não apenas por se encontrar nos limites entre a realidade e a ficção (como vimos), mas, sobretudo, pelo seu intuito humanizador.

\section{Referência}

PAMUK, Orhan. Heimatliche Gefühle in den Straßen São Paulos. Trad. Gerhard Meier. In: Der Blick aus meinem Fenster. Frankfurt: Fischer, 2008, p. 50-60. 